\title{
Palm oil substitution in hazelnut spread
}

\author{
ANIKÓ KOVÁCS* (i), LILLA KÖRMENDI and KATALIN BADAKNÉ KERTI
}

Hungarian University of Agriculture and Life Sciences, Villányi Street 29-43, 1118, Budapest, Hungary

\section{CONFERENCE FULL PAPER}

Received: June 1, 2021 - Accepted: August 10, 2021

Published online: September 1, 2021

(c) 2021 The Author(s)

\begin{abstract}
One of the most important components in spreads is the fat phase. The characteristics of the used fat determine most of the quality factors of the products such as viscosity, texture, colour, shelf life, etc. In these kinds of products, the commonly used fat is palm fat, however, in recent years it has had a bad press due to its negative environmental impact and health concerns. Therefore, the aim of our research was to develop a palm oil free hazelnut spread. We investigated the effect of replacing the fat in the fat phase with milk fat or coconut fat to the apparent viscosity, colour and texture properties of the product. According to our results the palm fat had the highest and coconut fat had the lowest viscosity. In texture analyses palm fat and milk fat showed no significant difference in hardness and in work of penetration. Coconut fat was significantly different in every texture attributes from the other samples. In the case of colour measurement all samples were significantly different. Despite the observed differences in some parameters the suitability of milk fat for hazelnut spread production should be further investigated (sensory analyses, shelf-life).
\end{abstract}

\section{KEYWORDS}

palm fat substitution, hazelnut spread, milk fat, coconut fat, viscosity

\section{INTRODUCTION}

Hazelnut spreads are considered as a complex multiphase system, which contain different dispersed solid particulars and a continuous fat phase (Glicerina et al., 2013). The physical attributes such as textural properties, viscosity, colour and flavour characteristic influence

\footnotetext{
*Corresponding author. E-mail: Kovacs.Aniko94@uni-mate.hu
} 
consumption of the products and the consumers' willingness to buy it (Shakerardekani et al., 2013). These products have to satisfy several aspects, such as good spreadability between ambient temperature, creamy taste and homogenous structure without the separation of the oil during storage (Lončarević et al., 2016; Aydemir et al., 2021). These attributes are highly influenced by the characteristics of the used fat (fatty acid composition, triacylglycerol content [TAG], solid fat content and crystal form). The three-dimension crystal network of a fat is capable to enclose liquid oil and air, which contributes to the structure of many products such as margarines and spreads. Also, the size of the fat crystals is responsible for the organoleptic characteristic of these kinds of products (Nguyen et al., 2020). The crystallization behaviour of a fat determines the consistency, sensory properties and appearance of fat-rich products (Marangoni et al., 2012).

The different confectionery creams and also the hazelnut spreads usually contain palm fat (Kaszab et al., 2020), which is the most consumed oil in the world among vegetable oils (Absalome et al., 2020). However, in recent years palm oil products received a bad press. On the one hand because of the negative impact on the eco-system such as deforestation and loss of biodiversity. On the other hand because the negative effect on the human health due to its high saturated fatty acid content (Ayompe et al., 2021; Absalome et al., 2020). According to a research (Plasek et al., 2021) the consumer's consumption of palm oil containing foods is highly affected by the perceived health effect of the food and the environmental impact of the production. This means that the labelling of the product with "palm oil free" claim could be beneficial for the factory. To satisfy this consumer demand the food producers have to substitute the palm fat with other fats. However, the replacement could be a challenging issue.

The traditional fats for sugar confectionaries are cocoa butter, milk fat and various vegetable oils such as coconut oil. Coconut fat is a complex mixture of triglycerides with carbon numbers 8 to 18 (C8-C18). It has a sharp melting profile and a good mouth feel (Talbot, 2014). Due to the lauric acid content and melting properties it is suitable for many food applications, for example margarine, cocoa butter substitutes and ice cream (Pantzaris \& Basiron, 2002).

Milk fat has a wide application and numerous benefits in food products, such as nutritional value, desirable mouthfeel and flavour enhancement (Ramel and Marangoni, 2019). It provides texture and flavour modification in milk chocolate. Milk fat contains more than 400 different fatty acids (Jensen and Clark, 1988). It has a unique fatty acid and triacylglycerol (TAG) content, it has a substantial content of short-chain fatty acids (particularly C4:0 and C6:0). Both the amount and location of these shorter-chain fatty acids are important and they influence the different properties of the milk fat, including melting and flavour (Metin and Hartel, 2012).

The aim of our study was to examine the opportunities of palm oil free hazelnut spreads. In our research we used coconut fat and milk fat for substitution of palm fat. We investigated the effect of changing the fat in the fat phase to the apparent viscosity, colour and texture properties of the products.

\section{MATERIALS AND METHODS}

For making our hazelnut spread we used the following ingredients: $50 \mathrm{~g}$ sugar, $25 \mathrm{~g}$ fat (palm fat for control sample, or coconut fat, or milk fat), $10.2 \mathrm{~g}$ hazelnut, $8.5 \mathrm{~g}$ cocoa powder, $5 \mathrm{~g}$ skim milk powder, 2 drops of vanillin aroma, 2 drops of lecithin and $0.3 \mathrm{~g}$ salt. All ingredients were 
commercially bought and the only difference among the samples was the type of the used fat. First, we weighed out all ingredients, we melted the fats in a microwave oven until reaching liquid state and we grinded the hazelnut in a household coffee grinder for around 2 min to achieve smaller practice size. Than we mixed the liquid fats with the dry materials in a plastic bowl by a spatula and for a smoother texture we used a laboratory sized melangeur for further mixing and texture formation of the creams. The mass was mixed for approx. half an hour. Then all the samples were stored in closed sample holders at room temperature in a dark cabinet till the analyses. We measured the viscosity, texture and colour of the spreads.

\section{Apparent viscosity}

The apparent viscosity of the samples was measured with Brookfield DV-E rotation viscometer, using the LV4 cylindrical measuring probe. The measurements were done at $35{ }^{\circ} \mathrm{C}$ with increasing rotation speed $(0-30 \mathrm{rpm})$ of the spindle. All samples were measured in triplicate. We calculated the shear stress and shear rate values in every case and on these results HerschelBulkley (1.) and Casson (2.) model were fitted (Figura and Teixeira, 2007).

1.) $\tau=\tau_{0}+K\left(\frac{d \gamma}{d t}\right)^{n}$
2.) $\tau^{\frac{1}{n}}=\tau_{0}^{\frac{1}{n}}+\left(\eta \frac{d \gamma}{d t}\right)^{\frac{1}{n}}$

$\tau$ - shear stess $[\mathrm{Pa}], \tau_{0}$ - yield stress $[\mathrm{Pa}], \mathrm{K}$ - consistency coefficient $[\mathrm{Pas}], \gamma$ - shear rate $\left(\mathrm{s}^{-1}\right), t-$ time $[\mathrm{s}], \eta$ - Casson viscosity [Pas].

\section{Colour}

The colour of the samples was measured with a Konica Minolta CR-310 tristimulus colour measurement device. The $L^{*}, a^{*}, b^{*}$ values were recorded for each sample. All samples were measured 5 times. The colour differences of the sample were calculated with the following equation.

$$
\Delta E=\sqrt{\Delta L^{2}+\Delta a^{2}+\Delta b^{2}}
$$

\section{Texture analyses}

The texture properties of the sample were measured at room temperature $\left(\sim 21{ }^{\circ} \mathrm{C}\right)$, using Stable Micro System TA-XT 2i universal texture measurement device. We recorded the hardness, the adhesiveness and the work of penetration parameters. For analyses, around $10 \mathrm{~g}$ samples were weighted in the measuring plastic cups and $45^{\circ}$ steel cone was attached to the measuring head. The probe was calibrated to $10 \mathrm{~mm}$ height above the sample holding cups. The cone approached the sample with $2 \mathrm{~mm} \cdot \mathrm{s}^{-1}$ speed and upon contact with the sample surface it was set to slow down to $1 \mathrm{~mm} \cdot \mathrm{s}^{-1}$. The penetration depth was set to $80 \%$ of the original height. At this point the measured force value was defined as hardness. The energy required to deform the samples to the given distance was determined as the work of penetration and it was calculated from the area under the positive curve. The adhesive 
characteristics of the samples were calculated from the withdrawal of the cone probe from the surface. Each sample was measured 7 times.

\section{Statistics}

Texture and colour data were analysed by one-way analysis of variance (one-way ANOVA). $P<0.05$ was considered statistically significant. To determine where the significant differences were, Tukey post-hoc tests were used.

\section{RESULT AND DISCUSSION}

\section{Texture analyses}

The spreadability is one of the most important attributes for consumers in the case of spreads. The different fat influenced the texture properties of the samples, which are shown in Fig. 1.

According to our results the milk fat and palm fat gave almost the same values in hardness and work of penetration, in adhesiveness milk fat gave the highest value. Coconut fat had the lowest texture parameters in every attributes. The statistical evaluation showed that there were no significant differences in hardness and in work between palm fat and milk fat. In adhesiveness all samples were significantly different. The coconut fat showed also significant difference in all other attributes according to the other samples. Based on our results we could conclude that the firmness of the spreads are highly determined by the type of the used fat. To identify which measured texture parameter is the most important for the consumer, sensory test should be done.

\section{Colour}

The spreads are usually sold in transparent packaging, which means that the appearance and therefore the colour of the products considerably influence the consumers first impression, whether they like it or not. The measured average $L^{*}, a^{*}$ and $b^{*}$ values of the samples are shown in Fig. 2.

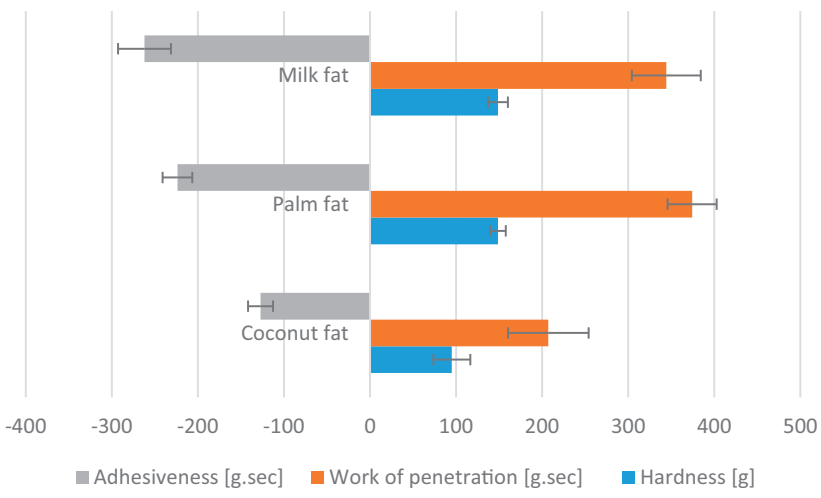

Fig. 1. Texture attributes of the different fat containing hazelnut spread samples $(n=7)$ 


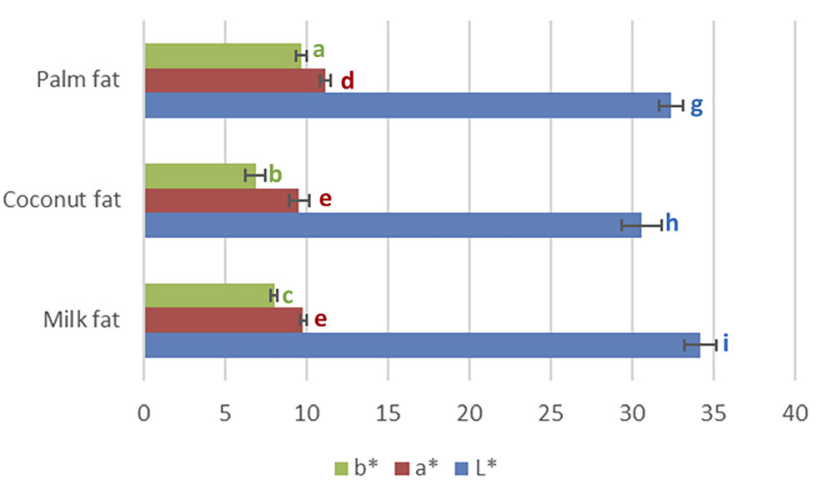

Fig. 2. Measured average colour parameters

The milk fat sample was the lightest and the coconut was the darkest. In $a^{*}$ and $b^{*}$ the palm fat sample gave the highest values which indicate the red and yellow values. In this attributes again the coconut sample had the lowest values. The samples showed significant differences in all parameters (ANOVA, post-hoc). There was only no difference in a* between the milk fat and coconut fat samples. The calculated visible colour differences $(\Delta \mathrm{E})$ showed that the differences among the samples could be seen by the human eyes. We could conclude that the colour of the sample is also affected by the type of the fat and its physical attributes. However, this is an objective test, the consumers' overall liking was not mirrored in this measurement, therefore a sensory test should be done.

\section{Apparent viscosity}

The viscosity of the different spreads is a very important attribute to the food factory. It influences the required energy for transporting the products by means of pumps. The average results of the viscosity measurement are shown in Fig. 3, with the increasing share rate all fat's viscosity decreased. We could see that they had shear thinning (a non-Newtonian fluid type) behaviour.

According to our result it can be seen that at the filling temperatures the palm fat had the highest viscosity while the coconut fat had the lowest. In a research (Aydemir et al., 2021) Casson and Herschel-Bulkley modell was successfully applied with high coefficients for glucose

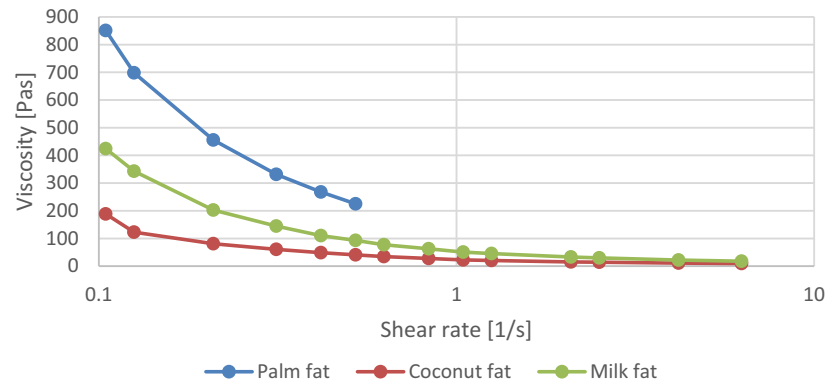

Fig. 3. Average viscosity results 
Table 1. Parameters of the fitted models

\begin{tabular}{lccccccr}
\hline & \multicolumn{3}{c}{ Casson model } & & \multicolumn{3}{c}{ Herschel-Bulkley model } \\
\cline { 2 - 4 } & Tau0 & eta & $\mathrm{n}$ & & Tau0 & $\mathrm{K}$ & $\mathrm{n}$ \\
\hline Milk fat & 39.93 & 9.85 & 1.17 & & 40.09 & 14.41 & 0.89 \\
Coconut fat & 16.29 & 6.63 & 1.09 & & 16.37 & 7.78 & 0.95 \\
Palm fat & 65.55 & 14.54 & 1.99 & & 77.05 & 71.67 & 0.86 \\
\hline
\end{tabular}

syrup substituted hazelnut spread. Based on this research we also applied these two models. The calculated parameters of them are shown in Table 1.

In our cases the calculated coefficients $\left(R^{2}\right)$ were also high in both models, the value was at least 0.994 in each case. Independently from the type of the used model, all samples were different from each other. Milk fat containing hazelnut cream behaved more similar to the standard cream, had closer viscosity values, than coconut cream.

\section{CONCLUSION}

The aim of the study was to find a possible replacement for palm fat in hazelnut spread. The effect of the change was monitored by measuring the texture, viscosity and colour of the samples. The measured parameters were influenced by the type of the used fat. In the colour parameters $\left(L^{*}, a^{*}, b^{*}\right)$, milk fat gave higher values then palm fat while coconut fat gave smaller results in every parameter. The samples were significantly different in all parameters, except in $\mathrm{a}^{*}$ between milk fat and coconut fat. In texture analyses milk fat showed no significant difference in hardness and in work of penetration to palm fat. In adhesiveness, all samples were different and milk fat gave the highest value. Coconut fat had the lowest values in every texture attributes and it was significantly different from the other samples in all texture parameters. In the case of viscosity, palm fat substituted samples gave lower values. The observed differences in every measured parameters could be due to the different physical properties of the applied fat, e.g., solid fat content, colour.

In conclusion, we could see that changing one ingredient in a food matrix could influence the different properties of the final product. However, to determine the suitability of different fats for hazelnut spread production further research is needed about the sensory characteristics and the shelf-life of the products.

\section{REFERENCES}

Absalome, M. A., Massara, C.-C., Alexandre, A. A., Gervais, K., Chantal, G. G.-A., Ferdinand, D., Rhedoor, A. J., Coulibaly, I., George, T. G., Brigitte, T., Marion, M., and Jean-Paul, C. (2020). Biochemical properties, nutritional values, health benefits and sustainability of palm oil. Biochimie, 178(2020): 8195. https://doi.org/10.1016/j.biochi.2020.09.019.

Aydemir, O., Beşir, A., and Aden, H. M. (2021). Textural and rheological characteristics of cocoa hazelnut cream partially substituted with glucose syrup. Eur. Food Sci. Eng. 2(1): 13-17. 
Ayompe, L. M., Schaafsma, M., and Egoh, B. N. (2021). Towards sustainable palm oil production: the positive and negative impacts on ecosystem services and human wellbeing. Journal of Cleaner Production, 278(2021): 1-11. https://doi.org/10.1016/j.jclepro.2020.123914.

Figura, L. O., and Teixeira, A. A (2007). Model functions for plastic fluids, Chapter 4.3.13. In: Food physics, Vol. 151. Springer-Verlag Berlin Heidelberg Publisher. ISBN 978-3-540-34194-9.

Glicerina, V., Balestra, F., Pinnavaia, G. G., Rosa, M. D., and Romani, S. (2013). Rheological characteristics of nut creams realized with different types and amounts of fats. Journal of Food Quality, 36(2013): 342350. https://doi.org/10.1111/jfq.12054.

Jensen, R.G., and Clark, R.M. (1988). Lipid composition and properties. In: Wong, N. (Ed.), Fundamentals of dairy chemistry, 3rd ed.. New York: Van Nostrand Reinhold Company, pp. 171-213. ISBN 978-14615-7050-9.

Kaszab, T., Bornemisza, L., and Badak-Kerti, K. (2020). Effect of the temperature on the rheological properties of compound coating. Progress in Agricultural Engineering Sciences, 16(S2): 127-139. https:// doi.org/10.1556/446.2020.20015.

Lončarević, I., Pajin, B., Petrović, J., Zarić, D., Sakač, M., Torbica, A., Lloyd, D. M., and Omorjan, R. (2016). The impact of sunflower and rapeseed lecithin on the rheological properties of spreadable cocoa cream. Journal of Food Engineering, 171(2016): 67-77. https://doi.org/10.1016/j.jfoodeng.2015.10.001.

Marangoni, A. G., Acevedo, N., Maleky, F., Co, E., Peyronel, F., Mazzanti, G, Quinn, B., and Pink, D. (2012). Structure and functionality of edible fats. Soft Matter, 8: 1275-1300, 2012. https://doi.org/10. 1039/C1SM06234D.

Metin, S., and Hartel, R.W. (2012). Milk fat and cocoa butter, chapter 15. In: Garti, N., and Widlak, N. (Eds.), Cocoa butter and related compounds. Academic Press and AOCS Press, pp. 365-392. ISBN 9780128043448.

Nguyen, V., Rimaux, T., Truong, V., Dewettinck, K., and Bockstaele, F. V. (2020). Fat crystallization of blends of palm oil and anhydrous milk fat: a comparison between static and dynamic-crystallization. Food Research International, 137(2020): 109412. https://doi.org/10.1016/j.foodres.2020.109412.

Pantzaris, T.P., and Basiron, Y. (2002). The lauric (coconut and palm kernel) oils. In: D Gustone, F. (Ed.), Vegetable oils in food technology: composition, properties and uses. USA: Blackwell Publishing: CRC Press, pp. 157-201. ISBN 9781444339925.

Plasek, B., Lakner, Z., Badak-Kerti, K., Kovács, A., and Temesi, Á. (2021). Perceived consequences: general or specific? The case of palm oil-free products. Sustainability, 13: 3550. https://doi.org/10.3390/ su13063550.

Ramel, P. R., and Marangoni, A. G. (2019). Microstructure of dairy fat products. Encyclopedia of Food Chemistry: 39-46, Academic Press https://doi.org/10.1016/B978-0-08-100596-5.21691-0.

Shakerardekani, A., Karim, R., Ghazali, H. M., and Chin, N. L. (2013). Textural, rheological and sensory properties and oxidative stability of nut spreads - a review. International Journal of Molecular Sciences 14(2): 4223-4241. https://doi.org/10.3390/ijms14024223.

Talbot, G. (2014). Fats for chocolate and sugar confectionery, Chapter 5. In: Rajah, K. K. (Ed.), Fats in food technology. Wiley-Blackwell Publishing, pp. 169-213. ISBN 978-1-118-78876-9.

Open Access. This is an open-access article distributed under the terms of the Creative Commons Attribution 4.0 International License (https://creativecommons.org/licenses/by/4.0/), which permits unrestricted use, distribution, and reproduction in any medium, provided the original author and source are credited, a link to the CC License is provided, and changes - if any - are indicated. (SID_1) 